\title{
Super-Twisting Control of the Duffing-Holmes Chaotic System
}

\section{Fayiz Abu Khadra}

Mechanical Engineering Department, King Abdulaziz University, Rabigh, Saudi Arabia

Email: fabukhadra@kau.edu.sa

How to cite this paper: Khadra, F.A. (2016) Super-Twisting Control of the Duffing-Holmes Chaotic System. International Journal of Modern Nonlinear Theory and Application, 5, 160-170.

http://dx.doi.org/10.4236/ijmnta.2016.54016

Received: September 17, 2016

Accepted: November 7, 2016

Published: November 10, 2016

Copyright $\odot 2016$ by author and Scientific Research Publishing Inc. This work is licensed under the Creative Commons Attribution International License (CC BY 4.0).

http://creativecommons.org/licenses/by/4.0/

\section{Abstract}

In this paper, a super twisting controller (STC) is designed to control the chaotic behavior of the Duffing-Holmes system in stabilization and tracking cases. Due to lack of availability of the performance evaluation of STC in controlling Duffing-Holmes system, this paper aims to test the performance of STC in controlling DuffingHolmes system. In order to achieve this control design, a modification of the conventional super twisting algorithm is adapted. Numerical simulations showed that the modified STC had high performance and ability to ensure robustness with respect to bounded external disturbances.

\section{Keywords}

Duffing-Holmes Chaotic System Super-Twisting Controller, Disturbance, Robustness

\section{Introduction}

Chaos's behavior is very sensitive to initial conditions. It has been utilized in many modern applications such as oscillators [1], biology [2], chemical reactions [3] [4], robotics [5] [6], lasers [7] [8], and neural networks [9] [10] [11], among other. This phenomenon attracts the attentions of scientists due to the varieties of its applications. Many research works have been made to analyze and control systems chaotic systems. Chaotic systems are used as a benchmark for testing the performance of controller. Different control techniques have been introduced to control chaotic systems, such as active control [12], adaptive control [13] [14], back stepping design [15], and sliding mode control [16] [17] [18].

The sliding mode control is a well-known control technique and its fundamentals are available in many books and manuscripts [19]. Sliding mode control has been applied to a wide range of problems in many processes and systems such as process control, 
robotics, electric drives and motion control [20] [21] [22] [23]. Since its first innovation, sliding mode control (SMC) has many attractive features to improve its performance such as invariance to matched uncertainties, simplicity in design, and robustness against perturbations. The idea of continuous-time SMC system is that sliding mode occurs on a selected sliding surface, where switching control is used to maintain the states on the surface. To reduce or avoid the chattering phenomenon High Order Sliding Modes (HOSM) [24] [25] can be used. They generalize the basic sliding mode idea, acting on the higher order time derivatives of the system. Second order sliding mode control (2-SMC) differs from the 1-SMC by including the first order derivative of the sliding variable while maintaining the same robustness and performance as that of the 1-SMC.

The super-twisting controller (STC) is the most known second order sliding mode controller. It provides finite time and exact convergence in the presence of bounded perturbations. Recently, a strict Lyapunov functions for the STC, to analyze its robustness for a wide class of perturbations, make the possibility to obtain an explicit relation for the controller design parameters has been introduced [26].

In this paper, the super twisting controller (STC) is used to control the chaotic behavior of the Duffing-Holmes system (DHS). The goal is to test the performance of STC in controlling DHS. Based in our best knowledge, there is a lack of studies that evaluate or test the STC performance in controlling DHSs.

The organization of rest of this article is as follows. Section 2 describes the DHS. Section 3 reviews the second order sliding mode method and describes the STC. In Section 4 , simulation results are provided to show the effectiveness of the proposed method in controlling the DHS. Section 5 concludes the paper.

\section{Duffing-Holmes Chaotic System}

A nonlinear oscillator with a cubic stiffness term to describe the hardening spring effect observed in many mechanical problems was introduced by Duffing. Duffing's equation has been modified in different manners afterwards such as Holmes. In this paper we consider a modified Duffing equation named Duffing-Holmes described as [27]:

$$
\ddot{x}(t)=p_{0} \dot{x}-p_{1} x-p_{2} x_{1}^{3}-q \cos (\omega t)=0
$$

where $x$ is the oscillation displacement, $p_{0}$ is the damping constant, $p_{1}$ is the linear stiffness constant, $p_{2}$ is the cubic stiffness constant, $q$ is the excitation amplitude, and $\omega$ is excitation frequency. By defining the states of Equation (1) $x_{1}=x$ and $x_{2}=\dot{x}$. Equation (1) can be rewritten as two first order ordinary differential equation as:

$$
\begin{aligned}
& \dot{x}_{1}(t)=x_{2}(t) \\
& \dot{x}_{2}(t)=p_{0} x_{1}(t)-p_{1} x_{2}(t)-p_{2} x_{1}^{3}(t)+q \cos (\omega t)+u(t)
\end{aligned}
$$

Extreme sensitivity to initial conditions is the fundamental characteristic of a chaotic system thus; small differences in the initial conditions can lead to differences in the system states response. To show this behavior, parameters of chaotic DHS is selected as $p_{0}=1, p_{1}=0.25, q=0.3$, and $\omega=1$. To show the effect of initial conditions Figure 1 
and Figure 2 are introduced, Figure 1 shows the response of Duffing system for the initial conditions of $x_{10}=0.3, x_{20}=0.1$. Figure 2 shows the response of the system for the initial conditions of $x_{10}=2, x_{20}=2$. Comparing the two figures it can be observed, how the system gives remarkable different response due to the mentioned values of the initial condition. The system has a chaotic behavior, when no control signal is applied.
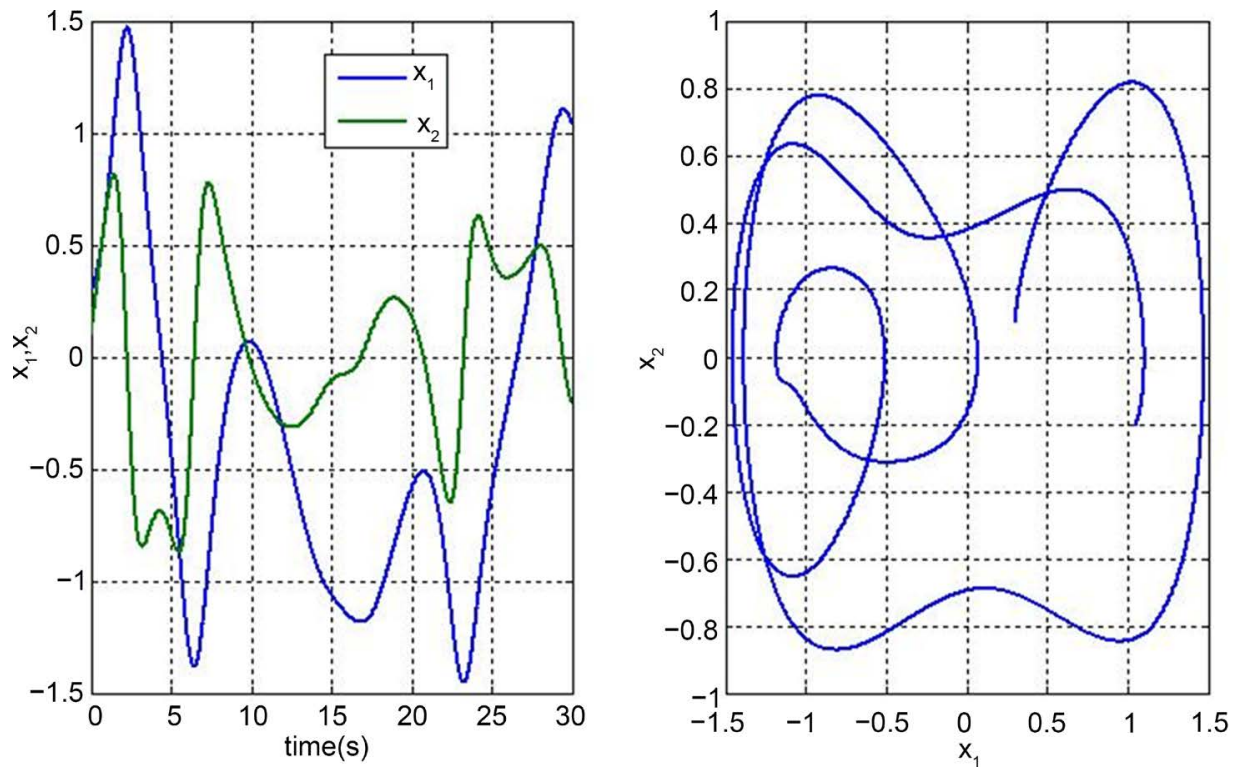

Figure 1. Chaotic behavior of DHS without the control input in 30 seconds for the initial condition $x_{10}=0.3, x_{20}=0.1$.
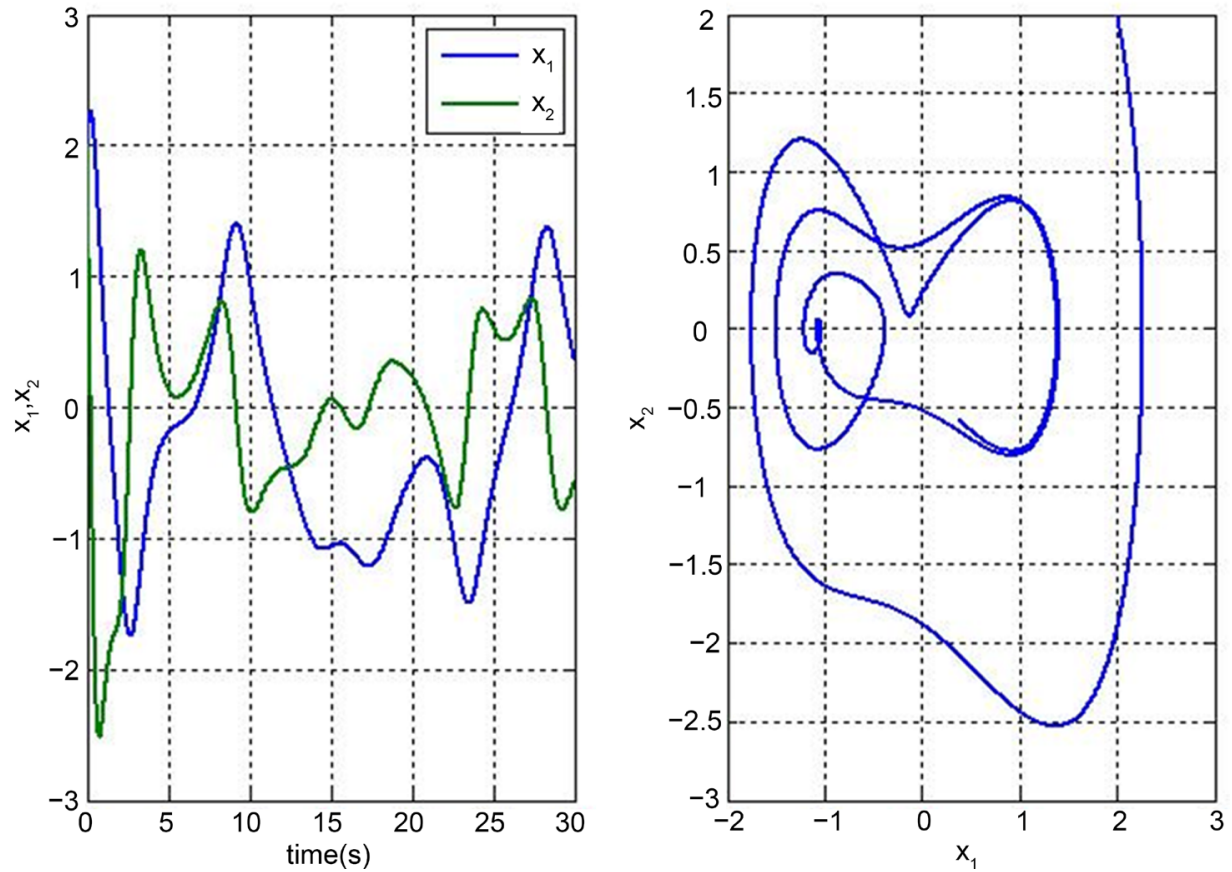

Figure 2. Chaotic behavior of DHS without the control input in 30 seconds for the initial condition $x_{10}=2, x_{20}=2$. 


\section{Super-Twisting Sliding Mode Controller}

The dynamic behavior of a second order nonlinear system can be written as follows:

$$
\ddot{x}(t)=f(x, t)+b(x, t) u(t)
$$

where $x(\mathrm{t})$, is the state and $u(\mathrm{t})$ is the control input vectors, respectively. $f(\mathrm{x}, \mathrm{t})$ and $b(\mathrm{x}$, $\mathrm{t})$ are unknown nonlinear functions of time and states. The functions $f(\mathrm{x}, \mathrm{t})$ and $b(\mathrm{x}, \mathrm{t})$ are not exactly known with upper bounded uncertainties. The control problem let the state $\mathrm{x}$ track a specified time dependent state $x_{\mathrm{r}}$.

$$
\sigma=x-x_{r}
$$

$\sigma \in \mathbb{R}$ in an output of (3) to be exactly stabilized in finite time. If the output $\sigma$ have a fixed and known relative degree $x \in \mathbb{R}^{n}$.For the positive constants $K_{\mathrm{m}}, K_{\mathrm{M}}$, and $C$ the following inequalities hold globally.

$$
0<K_{m} \leq b \leq K_{M},|f| \leq C
$$

2-SM controllers may be considered as controllers for the following differential inclusion [24]:

$$
\ddot{\sigma} \in[-C, C]+\left[K_{m}, K_{M}\right] u
$$

2-SM controllers allow to solve the problem of finite-time stabilization, the only information needed from the system is the output. The control $u(t)$ can be given as a sum of two components: The first one is defined by means of its discontinuous time derivative, while the another is a continuous function of the available sliding variable.

$$
u(t)=-k_{1} \varphi_{1}(\sigma(t))-k_{2} \int_{0}^{t} \varphi_{2}(\sigma(t)) \mathrm{dt}
$$

where $k_{1}$ and $k_{2}$ positive tuning parameters. Recently a modified super-twisting controller was proposed in [28]. In this modified controller the error dynamics $\Phi_{1}, \Phi_{2}$ are defined as follows:

$$
\begin{aligned}
& \varphi_{1}(\sigma)=|\sigma|^{\alpha} \operatorname{sign}(\sigma)+k_{3}|\sigma|^{1 / 2} \operatorname{sign}(\sigma) \\
& \varphi_{2}(\sigma)=\left[|\sigma|^{\alpha} \operatorname{sign}(\sigma)\right]^{2 \alpha-1}+\frac{k_{3}^{2}}{2 \alpha} \operatorname{sign}(\sigma)+k_{3}\left(1+\frac{1}{2 \alpha}\right)|\sigma|^{\alpha} \operatorname{sign}(\sigma)^{\alpha-1 / 2}
\end{aligned}
$$

where $k_{3}$ a positive tuning parameter. The signum function is defined as given below:

$$
\operatorname{sign}(\sigma)= \begin{cases}+1 & \sigma>0 \\ -1 & \sigma<0\end{cases}
$$

The 2-SMC method reduces a suitably-defined sliding variable to zero by the use of a discontinuous control action. The vanishing of the sliding variable guarantees the achievement of the control objective. The sliding variable is a linear combination between the tracking error and its first derivatives. In 1-SMC, the discontinuous control operates on the first time-derivative of the sliding variable. In 2-SM the discontinuous control affects the second derivative of the sliding variable. In this work the sliding variable $\sigma$ in Equation (7) is designed as follows:

$$
\sigma=e+c \dot{e}
$$


The error is defined as:

$$
e=x_{1}-x_{r}
$$

The constant $\mathrm{c}$ value can be selected to make the sliding variable converges to zero in a very short time. The first derivative of the error $\dot{e}$ can be calculated in real time by a differentiator. A recommended real time differentiator for industrial applications can be defined by its transfer function as given below:

$$
\frac{\dot{f}(s)}{f(s)}=\frac{s}{\tau s+1}
$$

where $\tau$ is a time constant. A small value for $\tau$ in the noise-free case, leads to an accurate estimation.

The Saturation block imposes upper and lower limits on the control signal. Output the signal, but only up to some limited magnitude, then caps the output to a value of $\mathrm{T}$. The saturation function is an odd function. The saturation function is given by:

$$
u(e)= \begin{cases}T & \text { if } e>T \\ e & \text { if }-T \leq e \leq T \\ -T & \text { if } e=-T\end{cases}
$$

The procedure described above can be represented by flowchart in Figure 3. Note that the measurement of first state in Equation 3 is only required, also the differentiator is used to obtain the first derivative of the error to close the control loop.

\section{Simulation Results}

In this section, the super twisting controller is used to control the DHS. This dynamic behavior will be controlled under the two schemes namely a set point and tracking tasks. To test the performance of the controller, a plant uncertainty representing the unmodeled dynamics or structural variation of the system, $\Delta f\left(x_{1}, x_{2}, t\right)$, the time-varying disturbance, $\delta(\mathrm{t})$ as external disturbance are added to the system. Hence, we have

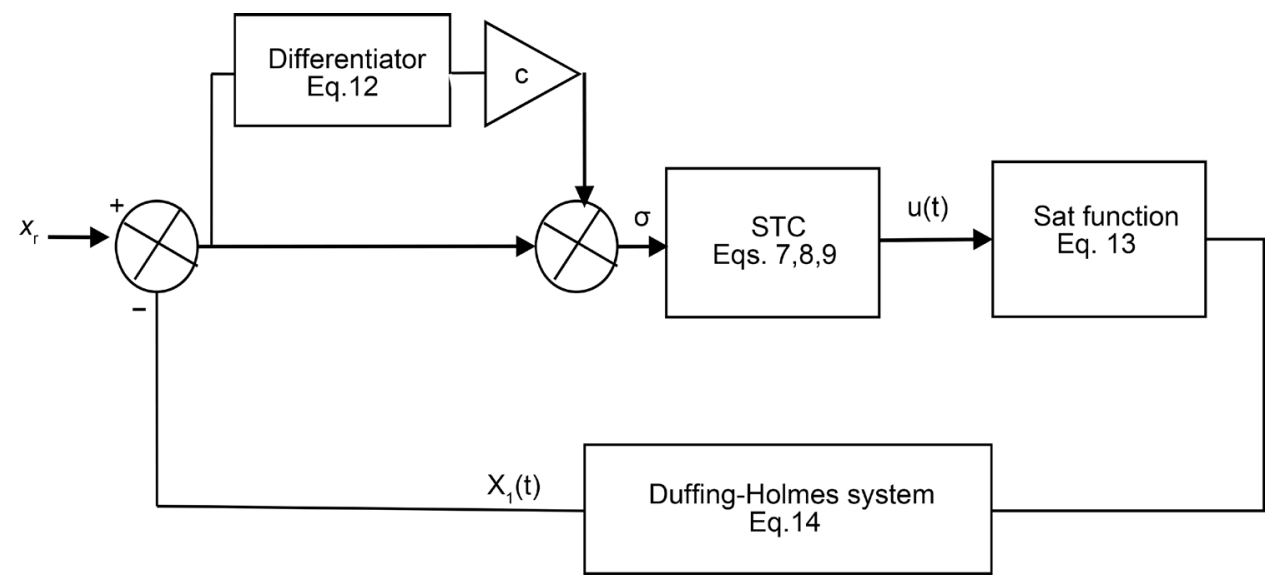

Figure 3. Schematic diagram of the closed loop control system. 


$$
\begin{aligned}
& \dot{x}_{1}(t)=x_{2}(t) \\
& \dot{x}_{2}(t)=p_{0} x_{1}(t)-p_{1} x_{2}(t)-p_{2} x_{1}^{3}(t)+q \cos (\omega t)+\Delta f\left(x_{1}, x_{2}, t\right)+\delta(t) u(t) \\
& y(t)=x_{1}(t)
\end{aligned}
$$

Then, the uncertainty, $\Delta f\left(x_{1}, x_{2}, t\right)$ for simulation purposes is modeled as follows:

$$
\Delta f\left(x_{1}, x_{2}, t\right)=0.1 \sin (t) \sqrt{x_{1}^{2}+x_{2}^{2}}
$$

The external disturbance $\delta(\mathrm{t})$ is given as:

$$
\delta(t)=0.1 \sin (t)
$$

In general, the uncertainty and the disturbance are assumed to be bounded and the corresponding upper bounds can be obtained as follows:

$$
\begin{gathered}
|f(\cdot)|=\left|x_{1}(t)-0.25 x_{2}(t)-x_{1}^{3}(t)+0.3 \cos (t)\right| \\
\leq\left|x_{1}(t)\right|+0.25\left|x_{2}(t)\right|+\left|x_{1}^{3}(t)\right|+0.3 \equiv \Delta f^{u}(\cdot) \\
|\delta(\cdot)|=|0.1 \sin (t)| \leq 0.1 \equiv \alpha
\end{gathered}
$$

\subsection{Setpoint}

Set point or stabilizing problem is to find a control $u(\mathrm{t})$ for stabilizing the state of the system at one of the unstable equilibrium points. This can be considered as a special case of the general tracking control with a constant reference signal. To demonstrate the performance of the STC, we present the results of the numerical simulations that have been obtained using MatLab/Simulink. The STC is used to set states $x_{1}$ and $x_{2}$ to the origin point $(0,0)$ via the control signal $u(t)$. For this purpose, a control signal $u(t)$ is activated at time $\mathrm{t}=10$ second. The parameters of the modified STC are taken as $k_{1}=8, k_{2}=8, k_{3}=1$, and $\alpha=2 / 3$.

The time-step used in the simulation is equal to 0.001 second. Figure 4 shows the

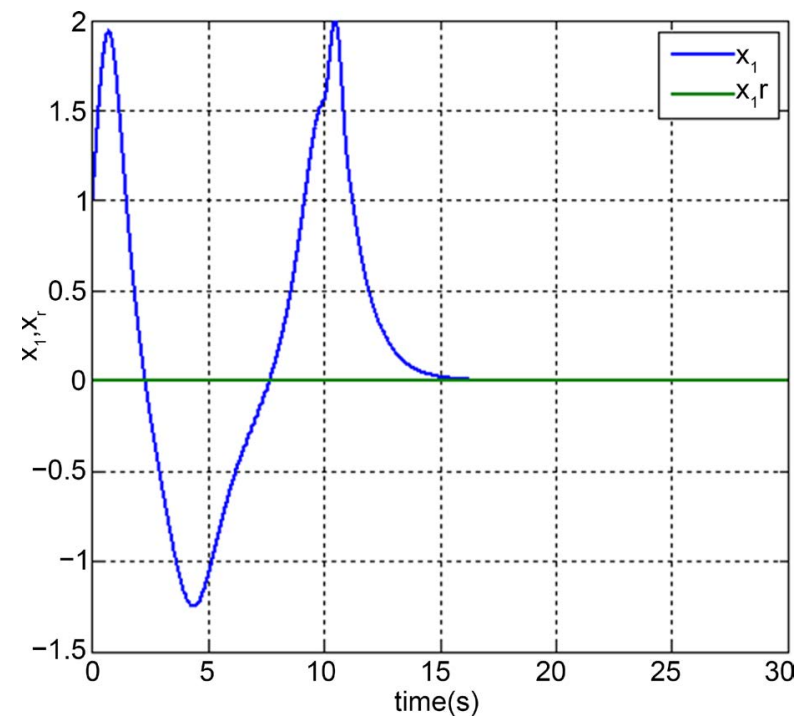

Figure 4. The time responses of the state $x_{1}$ of the controlled DHS. 
behavior of the controlled DHS. The states are initiates from the initial condition $x_{0}=$ $[1,2]$ and by applying the STC, the system states converge to the steady state equilibrium point i.e. $[0,0]$. The time needed for the first state $\mathrm{x}_{1}$ to reach zero error is approximately 5 seconds. Figure 5 shows the phase plane plot of the two states showing the behavior of the state before and after applying the control. The curve begins from the point $(1,2)$ converges toward the point $(0,0)$. Figure 6 shows the time history of the error function. Figure 7 shows the time response of control signal. The results presented in the figures show the good performance of the STC even though the DHS is subject to uncertainty and disturbances.

\subsection{Tracking}

The control objective is to solve the tracking problem stated below:

For any bounded reference trajectory $\mathrm{x}_{\mathrm{r}}$ whose derivative $\dot{x}_{r}$ and $\ddot{x}_{r}$ are bounded and piecewise continuous on $[0, \infty]$, Design a controller $u(t)$ that forces the output $\mathrm{y}=$ $\mathrm{x}$ to track $X_{\mathrm{r}}$ asymptotically as $\mathrm{t}$ goes to $\infty$ for any initial conditions $\left(x\left(t_{0}\right), \dot{x}\left(t_{0}\right) \in \mathbb{R}^{2}\right.$

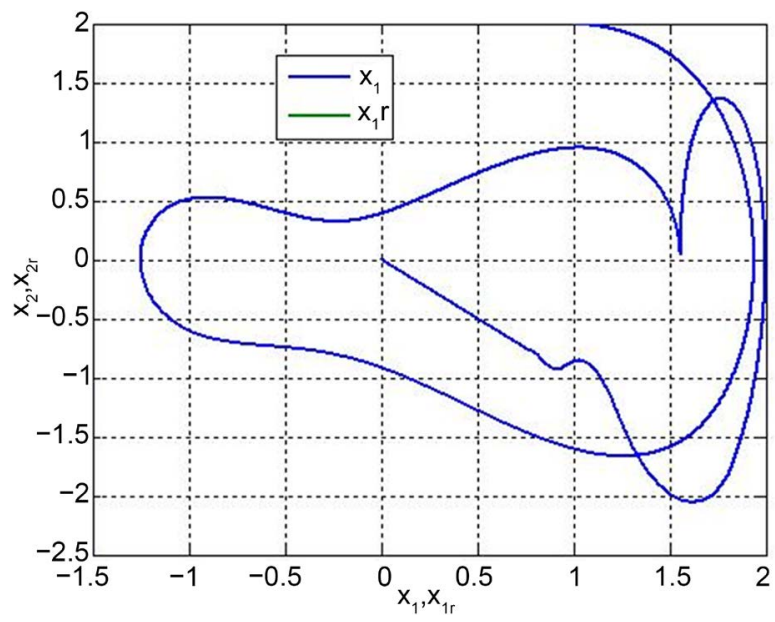

Figure 5. The phase-plane plot of controlled DHS.

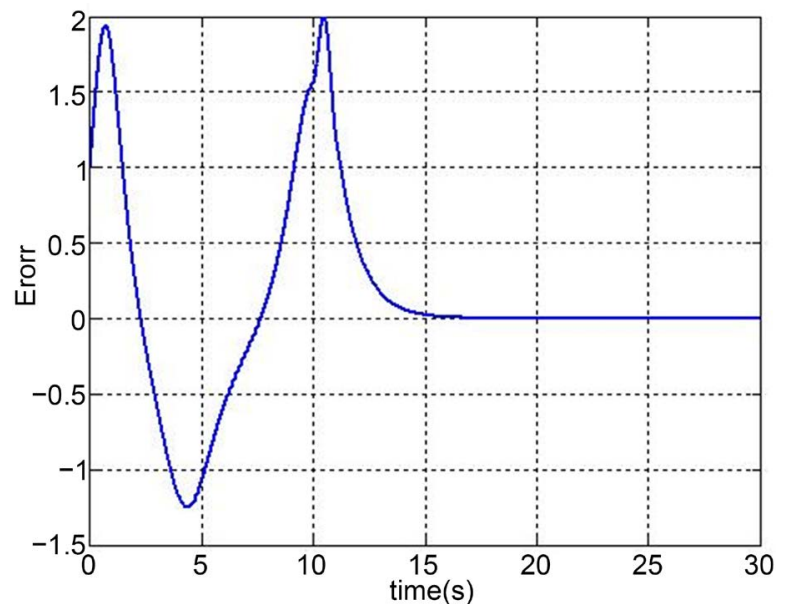

Figure 6. The time history of the error function. 
To test the performance of the STC in tracking task, the DHS is controlled to follow the trajectory given as:

$$
x_{r}=2 \cos (t)+\sin (t)
$$

The parameters of the DHS and the STC are similar to the previous section. Figure 8 shows the time responses of the state variables of the DHS. Figure 9 shows the time history for the tracking error, where the finite-time convergence to zero is clearly present. Note the error reached zero in a very short time approximately 5 seconds. Figure 10 shows the control effort required to follow the reference trajectory $x_{\mathrm{r}}$. Note that the control signal of the STC does not include chattering. A good view of tracking the DHS, the reference trajectory, is shown in phase plane plot depicted in Figure 11, where the beginning and ending points are clear in.

\section{Conclusion}

In this paper, the super-twisting controller has been applied to control a Duffing chaotic

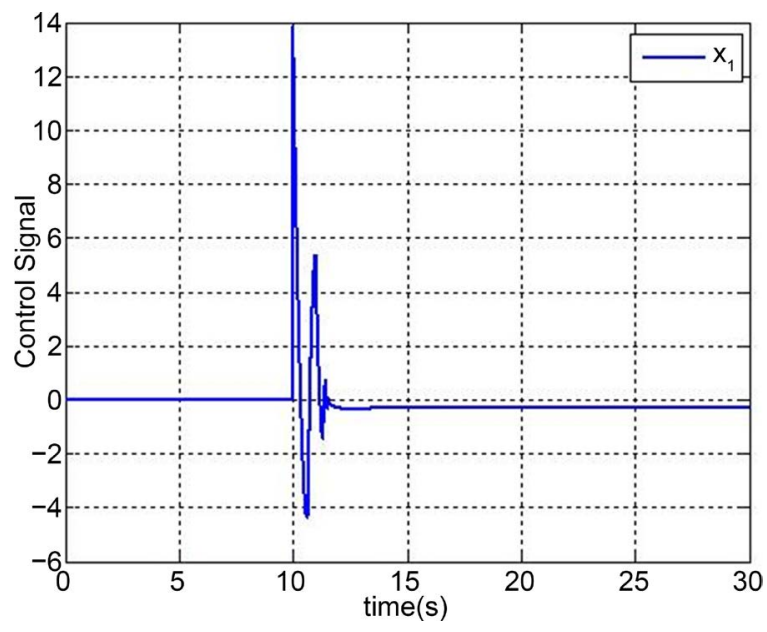

Figure 7. The time response of control input.

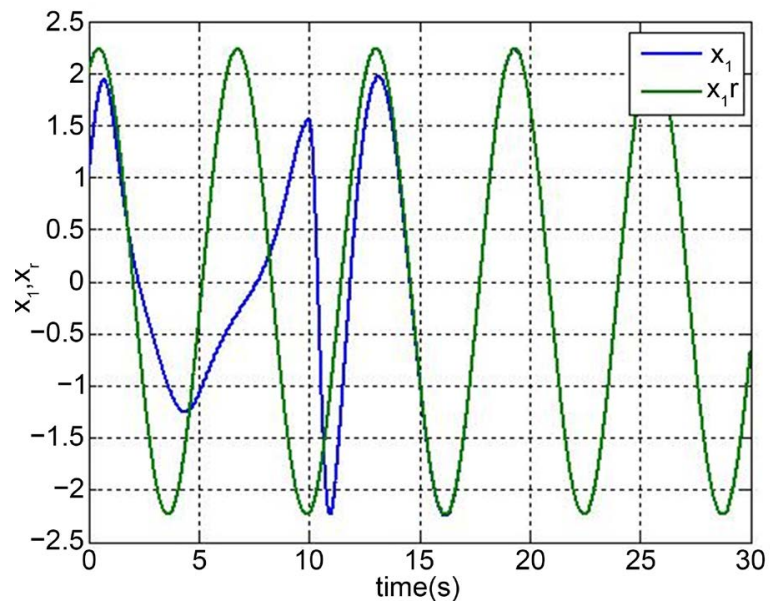

Figure 8. Controlled time response of the $X_{1}$. 


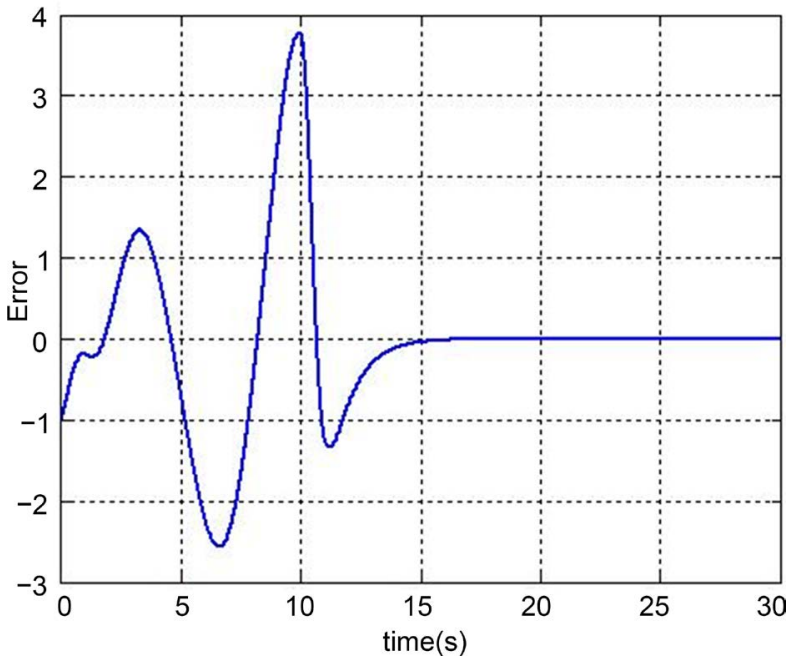

Figure 9. The error as function of time.

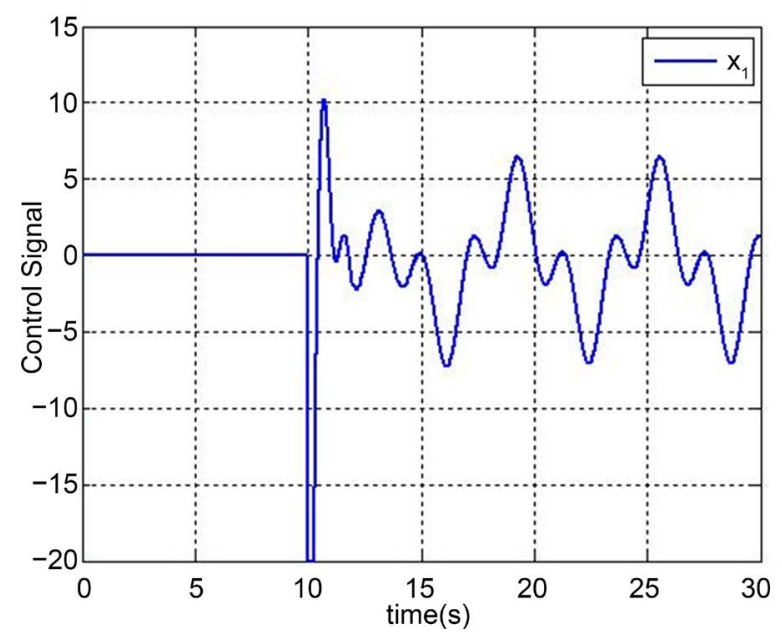

Figure 10. The time response of the control signal $u(t)$.

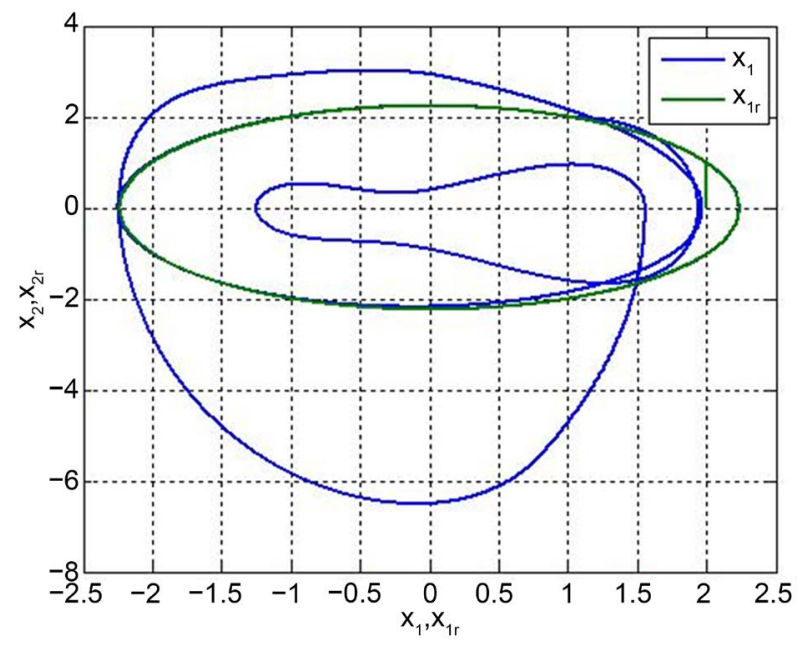

Figure 11. The phase-plane plot of controlled DHS. 
system. An appropriate sliding variable has been selected to solve the stabilization, tracking cases. The simulation results obtained clearly show the good performance of the controller in controlling a chaotic system with uncertainty to any arbitrarily desired trajectory with high accuracy. The steady state error was reduced to zero. The STC controller can be also applied to synchronization of chaos, since the problem can be changed into the nth order tracking problem of state. It has been observed that a proper selection of the control parameters influences the control effort and the error, so that a method for tuning the parameters is required.

\section{References}

[1] Sharma, A., Patidar, V., Purohit, G. and Sud, K.K. (2012) Effects on the Bifurcation and Chaos in Forced Duffing Oscillator Due to Nonlinear Damping. Communications in Nonlinear Science and Numerical Simulation, 17, 2254-2269. http://dx.doi.org/10.1016/j.cnsns.2011.10.032

[2] Kyriazis, M. (1991) Applications of Chaos Theory to the Molecular Biology of Aging. Experimental Gerontology, 26, 569-572. http://dx.doi.org/10.1016/0531-5565(91)90074-V

[3] Petrov, V., Gaspar, V., Masere, J. and Showalter, K. (1993) Controlling Chaos in the Belousov-Zhabotinsky Reaction. Nature, 361, 240-243. http://dx.doi.org/10.1038/361240a0

[4] Gaspard, P. (1999) Microscopic Chaos and Chemical Reactions. Physica A: Statistical Mechanics and Its Applications, 263, 315-328. http://dx.doi.org/10.1016/S0378-4371(98)00504-4

[5] Mondal, S. and Mahanta, C. (2014) Adaptive Second Order Terminal Sliding Mode Controller for Robotic Manipulators. Journal of the Franklin Institute, 351, 2356-2377. http://dx.doi.org/10.1016/j.jfranklin.2013.08.027

[6] Volos, C.K., Kyprianidis, I.M. and Stouboulos, I.N. (2013) Experimental Investigation on Coverage Performance of a Chaotic Autonomous Mobile Robot. Robotics and Autonomous Systems, 61, 1314-1322. http://dx.doi.org/10.1016/j.robot.2013.08.004

[7] Yuan, G., Zhang, X. and Wang, Z. (2014) Generation and Synchronization of FeedbackInduced Chaos in Semiconductor Ring Lasers by Injection-Locking. Optik-International Journal for Light and Electron Optics, 125, 1950-1953.

http://dx.doi.org/10.1016/j.ijleo.2013.11.007

[8] Li, N., Pan, W., Yan, L., Luo, B. and Zou, X. (2014) Enhanced Chaos Synchronization and Communication in Cascade-Coupled Semiconductor Ring Lasers. Communications in Nonlinear Science and Numerical Simulation, 19, 1874-1883.

http://dx.doi.org/10.1016/j.cnsns.2013.09.036

[9] Huang, X., Zhao, Z., Wang, Z. and Li, Y. (2012) Chaos and Hyperchaos in Fractional-Order Cellular Neural Networks. Neurocomputing, 94, 13-21. http://dx.doi.org/10.1016/j.neucom.2012.01.011

[10] Kaslik, E. and Sivasundaram, S. (2012) Nonlinear Dynamics and Chaos in Fractional-Order Neural Networks. Neural Networks, 32, 245-256. http://dx.doi.org/10.1016/j.neunet.2012.02.030

[11] Lian, S. and Chen, X. (2011) Traceable Content Protection Based on Chaos and Neural Networks. Applied Soft Computing, 11, 4293-4301. http://dx.doi.org/10.1016/j.asoc.2010.05.033

[12] Njah, A.N., Ojo, K.S., Adebayo, G.A. and Obawole, A.O. (2010) Generalized Control and Synchronization of Chaos in RCL-Shunted Josephson Junction Using Back Stepping De- 
sign. Physica C: Superconductivity, 470, 558-564.

http://dx.doi.org/10.1016/j.physc.2010.05.009

[13] Tu, J., He, H. and Xiong, P. (2014) Adaptive Backstepping Synchronization between Chaotic Systems with Unknown Lipschitz Constant. Applied Mathematics and Computation, 236, 10-18. http://dx.doi.org/10.1016/j.amc.2014.03.012

[14] Vaidyanathan, S. (2012) Adaptive Backstepping Controller and Synchronizer Design for Arneodo Chaotic System with Unknown Parameters. International Journal of Computer Science and Information Technology, 4, 145-159. http://dx.doi.org/10.5121/ijcsit.2012.4611

[15] Zhang, J., Li, C., Zhang, H. and Yu, J. (2004) Chaos Synchronization Using Single Variable Feed-Back Based on Backstepping Method. Chaos, Solitons \& Fractals, 21, 1183-1193. http://dx.doi.org/10.1016/j.chaos.2003.12.079

[16] Vaidyanathan, S. (2012) Sliding Mode Control Based Global Chaos Control of Liu-Liu-Liu-Su Chaotic System. International Journal of Control Theory and Applications, 5, 15-20.

[17] Lin, T.-C., Lee, T.-Y. and Balas, V.E. (2011) Adaptive Fuzzy Sliding Mode Control for Synchro-Nization of Uncertain Fractional Order Chaotic Systems. Chaos, Solitons \& Fractals, 44, 791-801. http://dx.doi.org/10.1016/j.chaos.2011.04.005

[18] Roopaei, M. and Jahromi, M.Z. (2008) Synchronization of Two Different Chaotic Systems Using Novel Adaptive Fuzzy Sliding Mode Control. Chaos, 18, Article ID: 033133.

[19] Utkin, V.I. (1992) Slides Modes in Control and Optimization. Springer, Berlin. http://dx.doi.org/10.1007/978-3-642-84379-2

[20] Sun, H., Li, S. and Sun, C. (2013) Finite Time Integral Sliding Mode Control of Hypersonic Vehicles. Nonlinear Dynamics, 73, 229-244. http://dx.doi.org/10.1007/s11071-013-0780-4

[21] Lu, K. and Xia, Y. (2013) Adaptive Attitude Tracking Control for Rigid Spacecraft with Finite-Time Convergence. Automatica, 49, 3591-3599.

http://dx.doi.org/10.1016/j.automatica.2013.09.001

[22] Qiao, Z., et al. (2013) New Sliding-Mode Observer for Position Sensorless Control of Permanent-Magnet Synchronous Motor. IEEE Transactions on Industrial Electronics, 60, 710 719. http://dx.doi.org/10.1109/TIE.2012.2206359

[23] Moradi, H., Saffar-Avval, M. and Bakhtiari-Nejad, F. (2012) Sliding Mode Control of Drum Water Level in an Industrial Boiler Unit with Time Varying Parameters: A Comparison with $H_{\infty}$-Robust Control Approach. Journal of Process Control, 22, 1844-1855. http://dx.doi.org/10.1016/j.jprocont.2012.10.003

[24] Levant, A. and Levantovsky, L.V. (1993) Sliding Order and Sliding Accuracy in Sliding Mode Control. International Journal of Control, 58, 1247-1263. http://dx.doi.org/10.1080/00207179308923053

[25] Fridman, L. and Levant, A. (2002) Higher Order Sliding Modes. Sliding Mode Control in Engineering, 11, 53-102.

[26] Moreno, J.A. and Osorio, M. (2012) Strict Lyapunov Functions for the Super-Twisting Algorithm. IEEE Transactions on Automatic Control, 57, 1035-1040. http://dx.doi.org/10.1109/TAC.2012.2186179

[27] Chen, G. and Yu, X. (Eds.) (2003) Chaos Control: Theory and Applications. Vol. 292, Springer, Berlin.

[28] Defoort, M. and Djemaï, M. (2012) A Lyapunov-Based Design of a Modified Super-Twisting Algorithm for the Heisenberg System. IMA Journal of Mathematical Control and Information, Online. 
Submit or recommend next manuscript to SCIRP and we will provide best service for you:

Accepting pre-submission inquiries through Email, Facebook, LinkedIn, Twitter, etc. A wide selection of journals (inclusive of 9 subjects, more than 200 journals)

Providing 24-hour high-quality service

User-friendly online submission system

Fair and swift peer-review system

Efficient typesetting and proofreading procedure

Display of the result of downloads and visits, as well as the number of cited articles

Maximum dissemination of your research work

Submit your manuscript at: http://papersubmission.scirp.org/

Or contact ijmnta@scirp.org 